\title{
Job search during the COVID-19 crisis is
}

\author{
Lena Hensvik $^{\mathrm{a}}$, Thomas Le Barbanchon ${ }^{\mathrm{b}, *}$, Roland Rathelot ${ }^{\mathrm{c}}$ \\ ${ }^{a}$ Uppsala University, Sweden \\ ${ }^{\mathrm{b}}$ Bocconi University, Italy \\ ${ }^{\mathrm{c}}$ University of Warwick, United Kingdom
}

\section{A R T I C L E I N F O}

\section{Article history:}

Received 31 July 2020

Revised 27 November 2020

Accepted 3 December 2020

Available online 19 December 2020

\section{JEL codes:}

$\mathrm{J} 22$

$\mathrm{J} 23$

$\mathrm{J} 21$

J62

J63

J64

E24

Keywords:

Coronavirus

Search intensity

Search direction

Labour demand shock

Job vacancies

Online job board

\begin{abstract}
A B S T R A C T
This paper measures the job-search responses to the COVID-19 pandemic using real-time data on vacancy postings and job ad views on Sweden's largest online job board. First, new vacancy postings drop by $40 \%$, similar to the US. Second, job seekers respond by searching less intensively, to the extent that effective labour market tightness increases during the first three months after the COVID outbreak. Third, they redirect their search towards less severely hit occupations, beyond what changes in vacancies would predict. Overall, these job-search responses have the potential to amplify the labour demand shock.
\end{abstract}

(C) 2020 The Author(s). Published by Elsevier B.V. This is an open access article under the CC BY-NC-ND license (http://creativecommons.org/licenses/by-nc-nd/4.0/).

\section{Introduction}

The COVID-19 pandemic has a large negative impact on economic activity. Labour markets are particularly impacted, with unemployment soaring and vacancy posting falling. One key question is how workers react to this crisis and search for new jobs. Depending on how job search intensity evolves following the

We would like to thank Arbetsförmedlingen for making the data available, Manuel Bagues, Tito Boeri, Christine Braun, Pierre Cahuc, Pascal Michaillat, Thijs van Rens as well as participants at Bocconi, Erasmus School of Economics, Glasgow, ICEF, Lugano, PSE, Warwick, OECD, Strathclyde e-seminars for helpful comments. We thank co-editor Johannes Spinnewijn and three anonymous reviewers for their helpful comments. We gratefully acknowledge financial support from the ERC StG 758190 "ESEARCH". Lena Hensvik received financial support from Forte and IFAU. Ana Teles provided excellent research assistance. All errors are our own. Hensvik is also affiliated with IFAU, CEPR, Le Barbanchon with CEPR, IGIER, IZA, J-PAL, Rathelot with CAGE, CEPR, J-PAL.

* Corresponding author.

E-mail addresses: lebarbanchon@unibocconi.it, thomas.le-barbanchon@ensae.fr (T. Le Barbanchon). shock, the supply side of the labour market may amplify or attenuate the consequences of the COVID-19 shock on labour demand.

This paper provides empirical evidence about the impact of the COVID-19 crisis on job search. We analyse real-time data on job search from Platsbanken.se, the largest online job board in Sweden operated by the Swedish Public Employment Service. We document how job seekers adjust the intensity and the direction of their search at the onset of the crisis. We also document the consequences for recruitment from the perspective of employers.

The Swedish context is particularly interesting given that many countries move away from strict lockdown policies towards more Swedish-style recommendations based on voluntary compliance to cope with the second wave of the pandemic in the Fall 2020. Despite the relative leniency of Swedish social-distancing measures, the number of new vacancies posted online decreases drastically in the aftermath of the crisis. Since early March 2020, employers post around $40 \%$ less new vacancies (see, e.g. Forsythe et al., 2020, for similar vacancy drop in the US). This leads to a drop in the stock of available vacancies available mid-April 2020 by $15 \%$. 
Within a week after the decrease in the number of new vacancies, the aggregate number of clicks on vacancies by Platsbanken users starts to decrease: by mid-April, aggregate search intensity decreases by around $40 \%$. Adopting the workers' perspective, we find that the average number of clicks per user decreases as well. Importantly, the reduction in job search intensity starts before the Swedish government increases the coverage and generosity of unemployment insurance and also holds in specifications that keep the composition of job seekers constant over time. Job search intensity goes back to pre-crisis levels in July 2020. The decline in search intensity in the weeks following the onset of the epidemic is consistent with COVID reducing the attractiveness of work, in particular through reduced health job amenities.

From the employers' perspective, we find that the average number of clicks per vacancy decreases by around $25 \%$, even when we control for detailed vacancy age, occupation and location. Even though employers face less competition to attract applicants (as fewer vacancies are online), vacancies receive less attention between mid-March 2020 and mid-June 2020 than they would have in 2019. In other words, effective labor market tightness increases during the first three months after the COVID outbreak. In search-and-matching models with rational expectations and constant marginal productivity, shocks on aggregate demand and on the health risk of employment lead to a decrease in equilibrium tightness. One possible reason for the opposite empirical result is that firms initially underestimate the sharp drop in job search activity and its consequences for job filling rates, as their environment reaches record level of uncertainty (Altig et al., 2020). In late June the impact on tightness vanishes.

The initial increase in tightness may contribute to depressing vacancies further. As vacancies receive fewer clicks, job filling is likely to slow down, increasing hiring costs. In a quantification exercise, we show that the reduction in job search activity is potentially an important amplification mechanism of the COVID19 crisis on labour market outcomes: the increase in labour market tightness translates into $11 \%$ fewer hires (holding the number of vacancies constant).

Beyond search intensity, we investigate the impact of the crisis on the direction of search. We split occupations into two groups resilient vs non-resilient - according to their evolution of vacancy inflows from January to April 2020. We find that the share of clicks towards resilient occupations or towards high home-working occupations increases. From the employers' perspective, the redirection of job search following the COVID shock has heterogeneous impacts. Employers posting jobs in resilient occupations receive more clicks per vacancy than employers posting in other occupations.

These results show that job seekers actively redirect their job search. If the direction of job search is sticky, i.e., job seekers do not change the occupations they click on, we expect resilient vacancies to receive relatively less attention than job ads from occupations where the number of vacancies becomes scarce. If job seekers just click on vacancies randomly, we expect all vacancies to receive the same number of clicks. Our results reject these models, but are compatible with models of directed job search, where job seekers strategically revise the value of employment attached to the different occupations as a result of the crisis.

The dynamic redirection of job search is likely to amplify labour demand shifts. As vacancies in resilient occupations attract more attention, recruitment processes may speed up, decreasing recruitment costs, which would induce these employers to open up new vacancies. The endogenous response of job search may thus facilitate labour market reallocation in the wake of the COVID crisis (Barrero et al., 2020).

We first contribute to the recent literature documenting the effects of the COVID-19 crisis on labour markets. Montenovo et al. (2020) and Mongey et al. (2020) document large job losses using the March CPS survey in the US. Job losses and hours reductions are confirmed in early April using homescan Nielsen data (Coibion et al., 2020), US payroll data (Cajner et al., 2020), household surveys (Adams-Prassl et al., 2020), and business surveys to firms (Bartik et al., 2020; Barrero et al., 2020). Brynjolfsson et al. (2020) and Bartik et al. (2020) use surveys to provide evidence for the switch to home-working during the first weeks of April. ${ }^{1}$ Forsythe et al. (2020) document the extent and heterogeneity in the drop of labour demand in the US using online vacancy data and new UI claims in March and April 2020. Our contribution to this literature is to combine real-time online data to provide the first available evidence on the effects of the COVID-19 crisis on the intensity and the direction of job search as well as the evolution of the effective labour market tightness. We are aware of two papers expanding on our work. Marinescu et al. (2020) use US data from Glassdoor to analyse the evolution of the applications-per-vacancy ratio in relation to the increase in unemployment benefits during the COVID pandemic. Bernstein et al. (2020) use US data from AngelList Talent (a job board specialised on tech employers) and show that job seekers broaden their search and aim for less risky employers.

Our analysis also relates more broadly to the empirical literature on job search that uses data from online job boards (Marinescu, 2017; Belot et al., 2018; Marinescu and Rathelot, 2018; Banfi and Villena-Roldan, 2019; Faberman and Kudlyak, 2019; Marinescu and Wolthoff, 2020; Kudlyak et al., 2020; Brown and Matsa, 2020). This literature does not document the response of online job search to labour market conditions, except Faberman and Kudlyak (2019). They find that the number of applications per job seeker is higher in metropolitan areas where unemployment is higher, using cross-sectional variation. In a withinuser design, we leverage the COVID shock to study the job search response, both its intensity and its selectivity.

The paper proceeds as follows. We describe the Swedish institutional background in Section 2 and the data in Section 3. We document the vacancy shock induced by the COVID crisis in Section 4. We estimate the response of job search intensity and of the direction of search in Section 5. We discuss the implications of our main results in Section 6. We conclude in Section 7.

\section{Background}

The first Swedish case of COVID-19 is confirmed on January 31st, 2020. Community spread is confirmed during the second week of March (the 11th week in 2020), and various measures are taken in the same week with the aim of slowing down the spread (or "flattening the curve"). These measures are relatively mild compared to other countries, they primarily rely on voluntary compliance with the social distancing guidelines of the Public Health Authority. During the second week of March, the Public Health Agency makes several formal announcements, and orders that all residents should keep a distance from each other, that high schools and universities should be closed, and that workers should work remotely as much as they can. Gatherings are also limited to 500 people; a restriction that is further tightened to 50 people two weeks later.

Since the beginning of March, the number of COVID-related deaths rises dramatically, amounting to over 3,000 deaths by the end of May. By this date, this makes Sweden one of the ten

\footnotetext{
1 Several papers provided ex ante analyses before ex-post evidence became available. Dingel and Neiman (2020) offers a description of US jobs, based on how teleworkable they are likely to be, while Mongey and Weinberg (2020) describe which workers would be more likely to be affected. Boeri et al. (2020) perform a similar exercise in Italy.
} 
countries most affected by COVID-19 worldwide in terms of deaths per million inhabitants (Johns Hopkins University, 2020).

Google's COVID-19 Mobility Reports (Google LLC, 2020) suggest that the public announcements are followed by substantial drops in time spent in workplaces, in retail and recreation places and in transit stations, while time spent at home and in parks increases (see Appendix A1a-A1f). ${ }^{2}$ The mobility response in Sweden is weaker than in European countries with stricter social distancing measures such as Norway, Denmark and France. It is rather similar to the drop in mobility in the US. Andersen et al. (2020) further show that consumption drops by $25 \%$ in Sweden, similar to the Danish drop which is only 4 percentage points stronger.

In response to the crisis, the Swedish government takes several measures to protect jobs and workers (Hensvik and Skans, 2020). Firms benefit from a payroll tax reduction and from short-time work (furlough) programs, which allow them to reduce their employees' working hours by 20,40 or 60 percent (up to 80 percent between March and May 2020). The furlough scheme is announced on March 16 and firms can use it from that day. However, the formal decision is taken during the first week of April and from then on, firms can apply, also retroactively.

Despite these measures, unemployment rises dramatically during the first weeks of March with a peak inflow of new unemployment spells during the first week of April (see Figs. $1 \mathrm{~b}$ and $\mathrm{d}$ for the evolution of the flow and stock of unemployed during this period). ${ }^{3}$

On the worker side, unemployment insurance coverage is extended and benefit levels are increased by April 13, 2020. The main components are a reduction of the workrequirements for UI eligibility from 80 to $60 \mathrm{~h} /$ month during 6 of the past 12 months and a lowered required duration of membership in UI funds from 12 to 3 months. The lowest benefit level (for those without UI membership) and the benefit cap are both increased quite substantially; the increases are around 30 percent relative to previous levels (Hensvik and Skans, 2020). We document below that job search responses take place from mid-March onward, before any changes in unemployment insurance generosity.

\section{Data}

Our primary data source is online data consisting of all posted job ads and the search activity on Sweden's largest job board Platsbanken.se. Platsbanken is operated by the Swedish Public Employment Service (PES). On Platsbanken.se, firms post vacancies and screen applicants (free of charge). Job seekers search vacancy listings, view job ads, and apply to posted vacancies. The coverage of Platsbanken.se is very large. According to Eurostat, the average number of vacant jobs in Sweden is 96,569 in 2019Q4. Using the same methodology as the source survey for the Eurostat statistics, we obtain 92,858 job openings in Platsbanken for the same period. The two counts align remarkably well.

On the vacancy side, the data contain rich information about the posted job, such as the occupation, location, expected hiring date, working hours, skill requirements, firms industry, etc. The data include the first date of publication on the website, when users can start to view the job ad, and the deadline date for applications. Swedish employers do not post wages on Platsbanken. We thus assign to each vacancy the 2018 mean wage of its occupation. ${ }^{4}$ We further add information about the home-working prevalence of occupations. Our primary measure is derived from the American

\footnotetext{
2 See also Born et al. (2020).

3 Juranek et al. (2020) document the labour market response in terms of unemployment and furlough spells in the Nordic countries. They find large increases in Denmark exactly around the time of the lockdown in week 11, and for Sweden a similar but somewhat less strong increase around two to three weeks thereafter.

${ }^{4}$ The wage data (Strukturlonestatistiken) are downloaded from Statistics Sweden's web page (www.scb.se). We use the 4-digit occupation codes.
}

Time Use Survey (ATUS). For each occupation, we compute the mean share of hours worked at home from 2011 to 2018 (Hensvik et al., 2020). As alternative home-working measures, we use the teleworkability indices based on ONET tasks from Dingel and Neiman (2020) and Mongey et al. (2020).

On the job seeker side, we observe when users open the webpage showing a specific vacancy. We denote this event a view or a click. Our data allow us to follow users over time via an anonymized identifier. For each user and click event, we have information about the vacancy identifier of the viewed ad and a time stamp. Importantly, our data contain the ad views of all users, both those searching from their computer and those using their phone. We do not have demographics information on Platsbanken.se users in our dataset. Based on a survey conducted in 2018, the Swedish PES estimates that $50 \%$ of users are registered unemployed.

The final dataset contains the search activity from January 2020 to July 2020, which amounts to more than 180 millions clicks on vacancies. We add search activity data from January 2019 to July 2019 as a control group. This allows to compute difference-indifference estimates of the COVID-19 crisis effects. On the labour demand side, we observe vacancies available on Platsbanken over the same period in 2020 and in 2019. This amounts to just around 1.2 millions clickable job ads.

\section{Labour demand during the COVID crisis}

Our primary measure of labour demand comes from vacancy postings. We measure changes in labour demand using the average daily inflow of new vacancies per week. Panel (a) in Fig. 1 shows the evolution of the daily inflow of vacancies from January to the end of July in 2020, and compares the 2020 and 2019 time series. ${ }^{5}$ The vacancy inflow is stable until the first week of March 2020 (the 10 th week in the year) and experiences a sharp and persistent drop in the second week of March (week 11), when the Swedish Public Health Authority announces social distancing guidelines (red solid vertical line in Fig. 1). The persistent drop in vacancy inflows leads to a gradual decline in the stock of vacancies (see Panel (c) in Fig. 1). To quantify the crisis impact, we estimate difference-indifference models that compare the change before and after week 10 in 2019 and $2020 .^{6}$ We obtain a reduction by $36 \%$ in the inflow of vacancies, and by $15 \%$ in the stock of vacancies. The magnitude of the decline in new vacancy postings is similar to what Forsythe et al. (2020) document in the US.

We corroborate the large labour demand shock in layoff and unemployment data. The monthly number of layoff notices increases sharply in March 2020 up to 10,000, compared to previous months or to the same period in 2019, when monthly notices were less than 1,000. Panel (b) in Fig. 1 shows that the number of new registrations of job seekers at the Swedish Public Employment Service increases since early March, by $49 \%$. Panel (d) confirms that the increase in unemployment inflows builds up into an higher stock of registered unemployed. We also note that the timing of the initial drop in vacancy postings coincides with the reduction in mobility, as measured by Google mobility reports.

We now describe the heterogeneity of the labour demand shock by industries and occupations.

Industry For each 1-digit industry, we compute the difference in the inflow of vacancies before and after week 10 in 2020, net of the inflow change over the same weeks in 2019. Here we restrict the sample until mid-May (week 20) to focus on the short-run impact of the COVID crisis. While the shock has a negative impact

\footnotetext{
${ }^{5}$ In our data, a vacancy or job ad may offer several similar jobs or positions. The evolution of daily inflow of posted jobs follows a similar pattern.

${ }^{6}$ Detailed difference-in-difference estimates for the whole Section 4 can be found
} in Appendix Tables B1 and B2, and in Appendix Fig. A2. 
(a) Inflow of vacancies

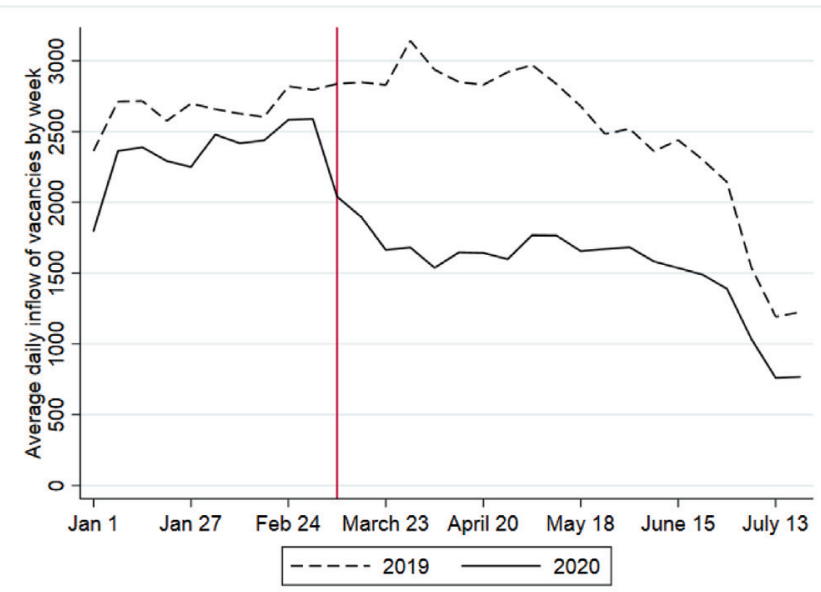

(c) Stock of vacancies

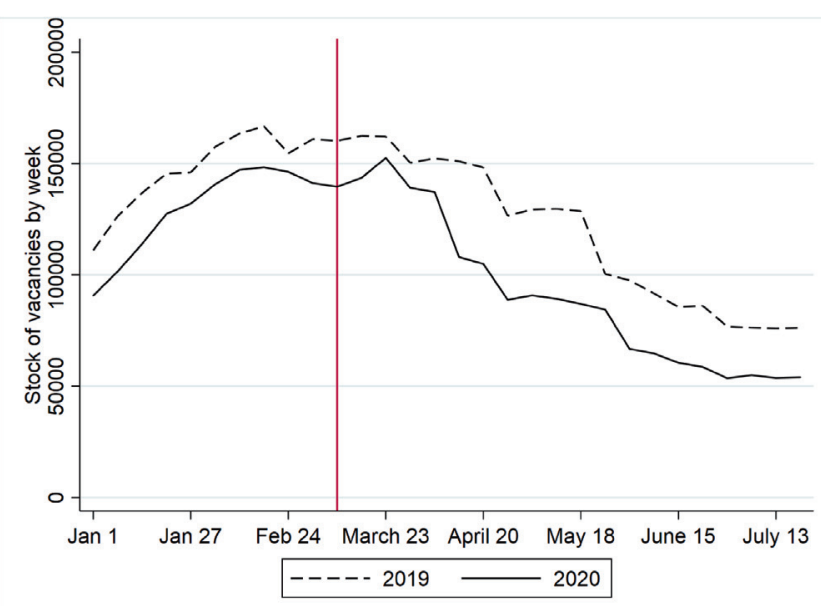

(e) Clicks on Platsbanken.se

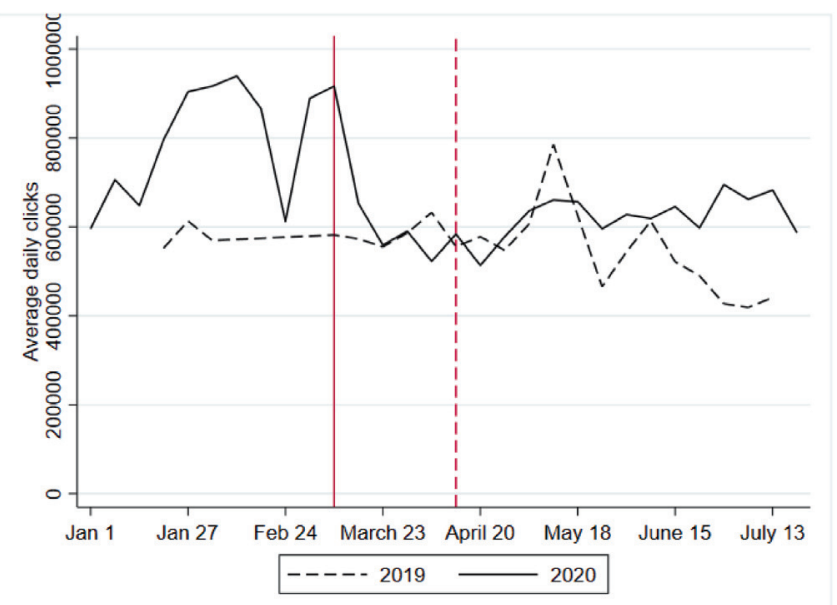

(b) Inflow of unemployed

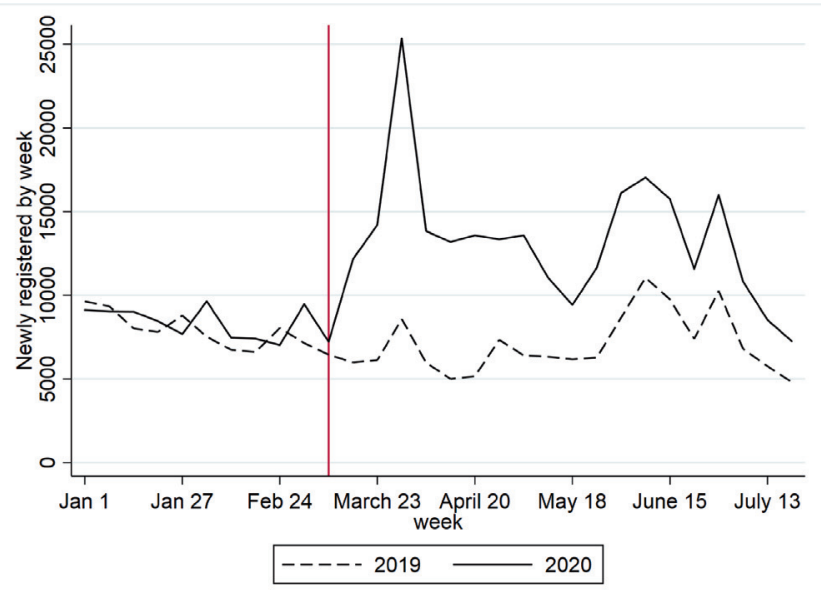

(d) Stock of unemployed

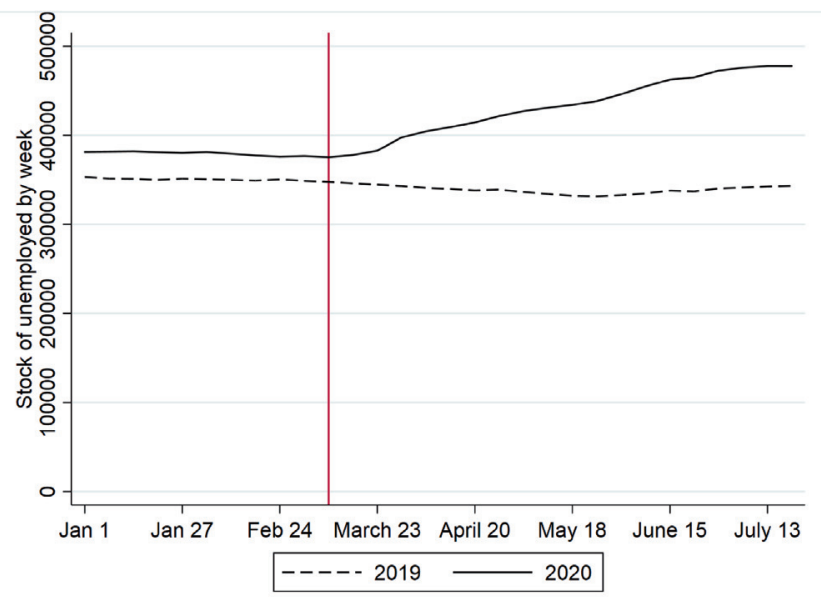

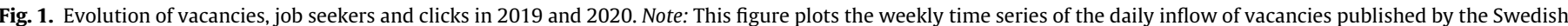

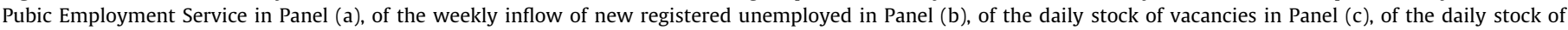

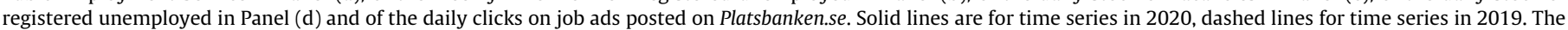

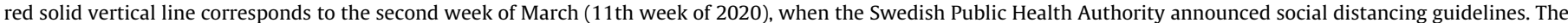

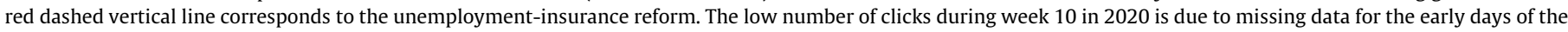
week, when search activity on the website is usually high.

on all industries, some industries are more severely affected. In particular, we see larger drops in industries where socialdistancing measures are likely to bind, such as hotels and restau- rants, entertainment and retail trade. The impact is less strong in the health and education sector, in real estate and in public administration and defence. 
At the outset of the crisis, the Swedish government has declared some industries as essential. We find that the decline in the number of posted vacancies is parallel in essential vs. non-essential industries. This could be explained by all industries anticipating the slow-down of future aggregate demand, and thus reducing hirings.

Occupation We now turn to differences in the labour demand shock by occupation. In Table 1 , we first isolate the ten most shrinking and the ten most resilient occupations according to the difference-in-difference estimates by 3-digit occupations. Among the ten occupations with the largest decrease in vacancy inflow, we find waiters and bartenders, dentists, and fast-food workers. Journalists and health care specialists are examples of occupations relatively resilient to the health crisis. The fraction of new posted vacancies in health care occupations increases sharply after midMarch. ${ }^{7}$ On average, the home-working share of posted vacancies increases by 0.5 percentage points after the shock. ${ }^{8}$ Finally, the drop in vacancy postings is larger in occupations at the bottom of the wage distribution.

\section{Job search during the COVID crisis}

\subsection{Aggregate trend}

This section describes the aggregate evolution in job search. In Panel (e) of Fig. 1, we plot the daily number of clicks on Platsbanken, averaged week by week. In mid-March 2020, daily clicks decrease sharply, reaching a drop by around $40 \%$ in mid-April 2020. This contrasts with the evolution of aggregate clicks in 2019 over the same period.

The evolution of aggregate vacancy views is driven by both the number of job ads available on the website and the search behaviour of workers. The previous section shows that firms post fewer vacancies since early March 2020, which contributes to lower aggregate clicks even when workers exert the same job search effort. To account for the evolution of available jobs, we turn to econometric models in which the outcomes are the number of daily clicks per user and daily clicks per vacancy.

\subsection{Main econometric specification}

We first take the job seeker perspective, and consider as outcome daily clicks per user. We estimate the following equation:

$y_{i d}=\sum_{w} \beta_{w} \mathbf{1}[d \in w]+\mu_{i}+\gamma X_{i d}+\varepsilon_{i d}$

where $y_{i d}$ is the log of the number of times user $i$ clicks on vacancies during day $d, \beta_{w}$ are week fixed effects and the parameters of interest, $\mu_{i}$ are user fixed effects, and $X_{i d}$ are dummies for the days of the week, public holidays and for the number of days since the user first clicks on Platsbanken. This last covariate controls for duration dependence in job search behaviour (Faberman and Kudlyak, 2019). In the main specification, the estimation sample includes user-days $(i, d)$ when there is at least one click. We thus focus on the intensive margin of job search behaviour. In additional specifications reported in the Appendix, we also consider the extensive margin of job search, whether users click at least once in a given day. We then estimate Poisson models of the number of clicks, which allows us to keep in the estimation sample the user-days $(i, d)$ when there is no click.

\footnotetext{
7 We plot in Appendix Fig. A3 the weekly evolution of vacancy types.

8 We find that the ONET task-based measures of Dingel and Neiman (2020) and of Mongey et al. (2020) are not as predictive of the differences in the evolution of labour demand across Swedish occupations as our time-use measure in Hensvik et al. (2020)
}

Table 1

Ten most resilient and least resilient occupations: difference-in-difference estimates.

\begin{tabular}{|c|c|c|}
\hline Occupation label & $\begin{array}{c}\text { Estimated change } \\
\text { in } \\
\text { vacancy inflow } \\
\text { (log) } \\
\text { Pre- vs. Post week } \\
\text { 10, } \\
2019 \text { vs. } 2020\end{array}$ & std. err \\
\hline \multicolumn{3}{|l|}{ Ten least resilient } \\
\hline Waiters and bartenders & -2.252 & $(0.215)$ \\
\hline Dentists & -1.258 & $(0.243)$ \\
\hline $\begin{array}{l}\text { Fast-food workers, food preparation } \\
\text { assistants }\end{array}$ & -1.230 & $(0.152)$ \\
\hline Shop staff & -1.229 & $(0.194)$ \\
\hline Culinary associate professionals & -1.133 & $(0.199)$ \\
\hline Hairdressers, beauty and body therapists & -1.128 & $(0.268)$ \\
\hline Postmen and postal facility workers & -1.105 & $(0.293)$ \\
\hline $\begin{array}{l}\text { Athletes, fitness instructors and recreational } \\
\text { workers }\end{array}$ & -1.035 & $(0.435)$ \\
\hline Cooks and cold-buffet managers & -1.007 & $(0.153)$ \\
\hline Dental nurses & -0.996 & $(0.244)$ \\
\hline \multicolumn{3}{|l|}{ Ten most resilient } \\
\hline Authors, journalists and linguists & 0.075 & $(0.278)$ \\
\hline $\begin{array}{l}\text { Specialists in health care not elsewhere } \\
\text { classified }\end{array}$ & -0.058 & $(0.237)$ \\
\hline Nursing professionals & -0.074 & $(0.167)$ \\
\hline Personal care workers in health services & -0.105 & $(0.159)$ \\
\hline University and higher education teachers & -0.132 & $(0.174)$ \\
\hline Primary- and pre-school teachers & -0.144 & $(0.120)$ \\
\hline Medical and pharmaceutical technicians & -0.145 & $(0.198)$ \\
\hline Social work and counselling professionals & -0.180 & $(0.122)$ \\
\hline Electrical equipment installers and repairers & -0.182 & $(0.148)$ \\
\hline Car, van and motorcycle drivers & -0.191 & $(0.336)$ \\
\hline
\end{tabular}

Note: This table reports the 10 most/least shrinking occupations when we rank occupations according to their coefficients from the following model:

$\ln \left(\right.$ Inflow $\left._{w, y, o}\right)=\sum_{o} \theta_{o}$ Treat $_{y} \times$ Post $_{w} \times$ Occ $\left._{o}\right)+\lambda_{y_{o}}+\lambda_{w o}+\lambda_{w y}+\epsilon_{w y o}$, where Inflow is the inflow of vacancy ads belonging to occupation 0 ; Post is a dummy taking the value one if the week is between week 11-20 (the comparison is week 1-10); Treat is a dummy taking the value one if year $=2020 ; O c c_{0}$ are occupation dummies; and $\lambda_{y_{0}}$ are year $\times$ occupation fixed effects; $\lambda_{w o}$ are week $\times$ occupation fixed effects and $\lambda_{w y}$ are week $\times$ year fixed effects. To make the table informative, we display occupations where the pre-COVID vacancy share is at least 0.2 percent. With such large changes, log changes are no longer a first order approximation of percent change. For example, for dentists, the -1.26 log change translates into a $72 \%$ decrease.

Similarly, from the vacancy perspective, we estimate the following equation:

$y_{j d}=\sum_{w} \beta_{w} \mathbf{1}[d \in w]+\gamma X_{j d}+\varepsilon_{j d}$

where $y_{j d}$ is the log of the number of clicks on vacancy $j$ during day $d, \beta_{w}$ are week fixed effects, $X_{j d}$ are dummies for the days of the week, public holidays and characteristics of the vacancy, including dummies for the first day and the last day of publication, as well as a flexible functional transformation of number of days since publication, which controls for duration dependence in clicks. $X_{j d}$ also include dummies for vacancy occupation (395 codes) and municipality (382 codes). Our main estimation sample includes for each vacancy the days with at least one click. We also check the robustness of the results at the extensive margin in additional specifications reported in the Appendix.

We estimate each model separately for years 2019 and 2020, and we take the first week of February (week 6) as the reference. We cluster inference at the user level for Regression (1), and at the vacancy level for Regression (2).

\subsection{Individual search intensity and vacancy-level tightness}

Fig. 2 plots the week effects from Regressions (1) and (2). Panel (a) in Fig. 2 shows the estimates of the coefficients on the week 
(a) Clicks per user, without user fixed effects

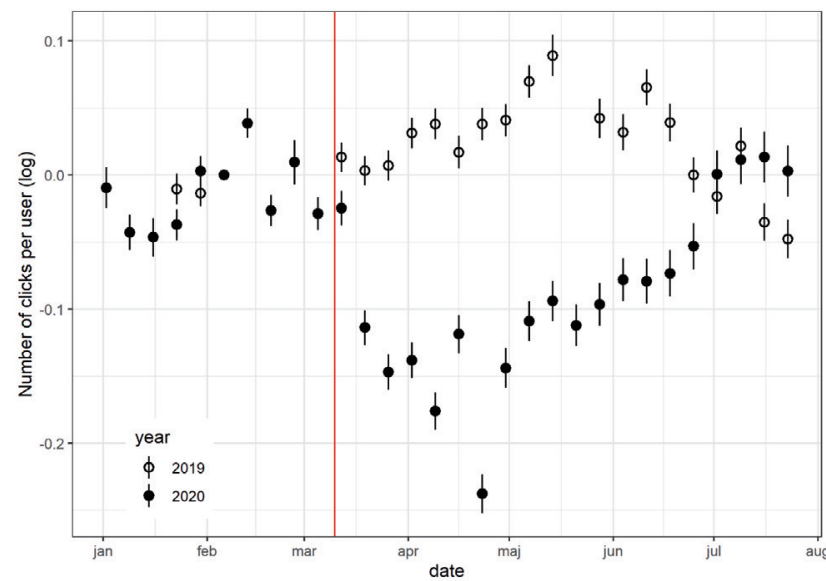

(c) Clicks per vacancy

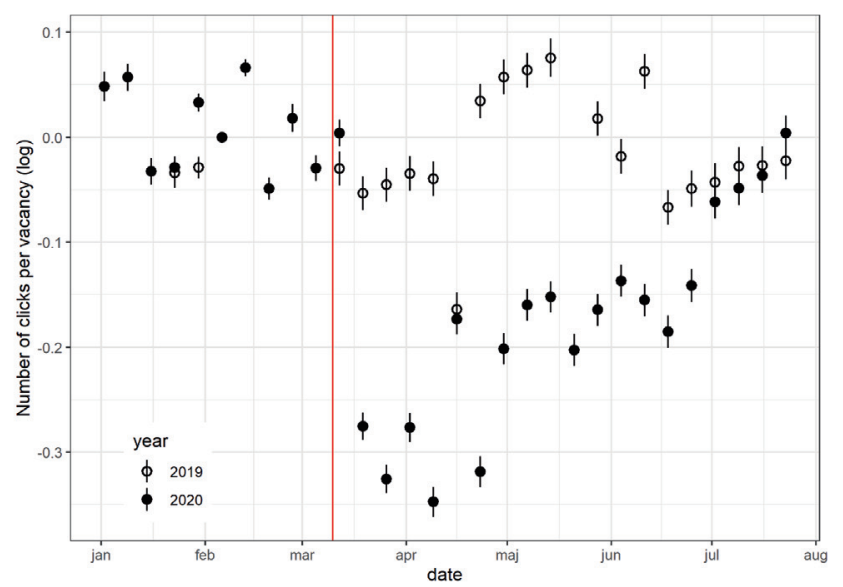

(b) Clicks per user, with user fixed effects

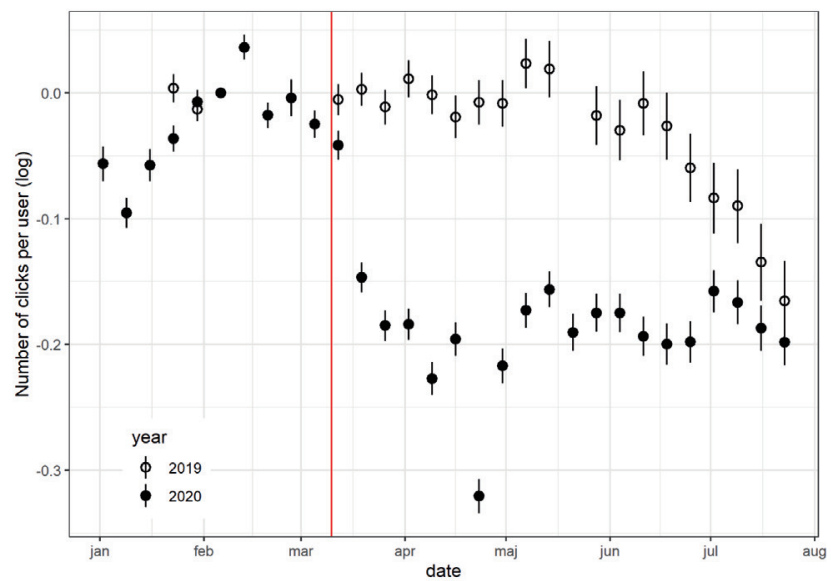

(d) Clicks per vacancy, with vacancy controls

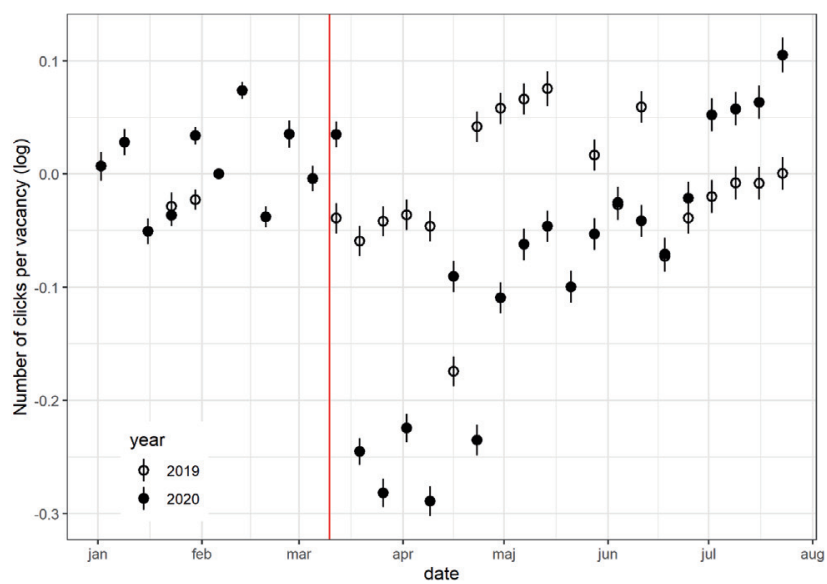

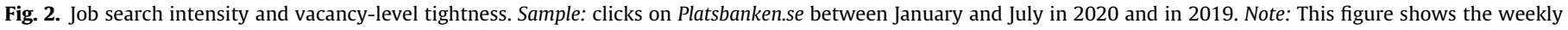

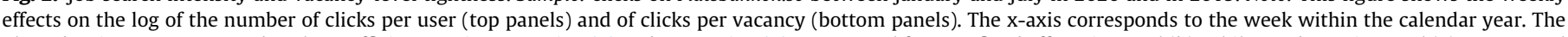

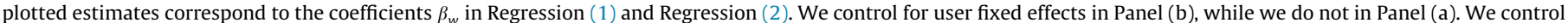

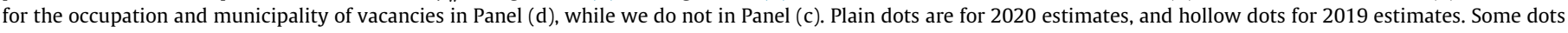

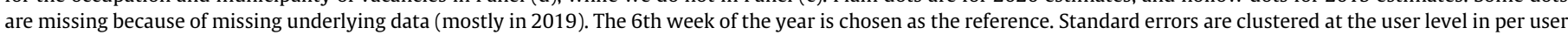

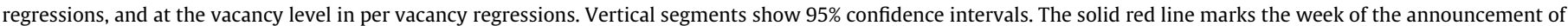
the Public Health Agency's social distancing recommendations.

dummies in the regression where the log number of clicks per job seeker is the outcome, and where there are no user fixed effects. Conditional on clicking at least once in the day, the average number of clicks per user is fairly stable until mid-March 2020: it hovers between $-5 \%$ and $2.5 \%$ (in deviation from week 6 ). One week after the announcement of social distancing recommendations and the simultaneous vacancy drop (week 12), the number of clicks experiences a sharp decrease of around 15\% (plain dots). Given the large sample size, the drop is highly statistically significant. The drop is not due to seasonal effects, as the same estimates for year 2019 (hollow dots) do not show any decline in the number of clicks per user. The drop persists until the end of May, after which average clicks per user start to increase and gradually converge back to the pre-COVID level (and the 2019 level).

The decline of clicks per user could be partly due to the decrease in the number of vacancies available on the job board. In Panel (c) of Fig. 2, we run Regression (2) of the log number of daily clicks per vacancy in a specification with the vacancy age controls but without the vacancy occupation and municipality controls. We control for these composition effects in Panel (d). In Panel (c), we find a sharp drop in daily clicks per vacancy of around 30\% after mid-
March 2020. Daily clicks per vacancy remain at low levels (around $-20 \%$ ) until the end of June 2020 . The shift is very clear and significant, compared to the situation before the social distancing announcements, and to the same weeks in 2019. From the perspective of individual vacancies, the situation is paradoxical. Even though vacancies face less competition, as the total number of vacancies decreases, and face a larger pool of potential applicants, as the number of incoming job seekers increases sharply, our analysis shows that each vacancy receives less attention in the aftermath of the crisis. The effective number of job seekers per vacancy appears to be smaller after mid-March. In other words, vacancy-level tightness increases. This result could be explained by the impact of the crisis on individual behaviour, or could be due to composition effects. Both the pool of potential applicants and available vacancies may become more negatively selected since March 2020, towards low-search-effort job seekers and low-quality jobs respectively.

In the right-hand side panels of Fig. 2, we control for composition effects by introducing user fixed effects (Panel b) and vacancy characteristics (Panel d). We find a significant drop in the clicks per user from mid-March on of around $20 \%$. The magnitude of the 
effect is larger by 5 percentage points than the estimate from the regression without fixed effects. Even when identification is driven by users actively searching in the weeks before and after the social distancing announcements, we find a decline in job search. In Panel (d), the number of clicks per vacancy drops by around $25 \%$ from mid-March on. Controlling for vacancy characteristics lowers the magnitude of the clicks decline by 5 percentage points and leads to a faster convergence to usual click levels. Already in June 2020 , clicks per vacancy are less than $10 \%$ lower than early-2020 levels, and aligned to June-2019 levels. Overall, this provides strong supportive evidence for a persistent reduction in job search intensity fading out within three months after the COVID shock.

We check the robustness of our results, when considering both the intensive and extensive margins. We estimate Poisson models counting the number of clicks either per user or per vacancy. Detailed estimation results are available in Appendix Fig. A4. We find similar time-series breaks in mid-March 2020 when clicks per user decrease by around $30 \%$ and clicks per vacancy decreases by $40 \%$.

\subsection{Impact on the direction of job search}

While job search becomes less intense, one key question is whether it redirects towards specific jobs. How does the direction of search change in the wake of the COVID crisis? Does any redirection of job search lead to differential impact on recruitment across employers?.

We first adopt the user perspective. We construct two searchdirection outcomes $y_{i d}$ characterizing the occupations of the vacancies that user $i$ clicks during day $d$ :

- the average home-working index (Hensvik et al., 2020),

- the average resilience index, i.e. the difference-in-difference estimate corresponding to the impact of the crisis shock on the inflow of vacancies in that occupation until mid-May (see Table 1).

We run within-user Regressions (1) with the search-direction measures as outcomes, and we plot the estimates of the week fixed effects in the upper panels of Fig. 3. Panel (a) shows that compared to pre-COVID levels the targeted home-working index increases by 0.005 by the end of April 2020 (3\% of the index mean). The effect is half smaller in magnitude when we use the 2019 estimates as comparison group, but still statistically significant. Panel (b) shows that the targeted resilience index sharply increases by 0.08 during March 2020, and then gradually converges back to pre-crisis levels. The average vacancy clicked on in April 2020 belongs to an occupation whose change in aggregate number of vacancy creation is $8 \%$ above the trend. The gradual convergence after May is partly mechanical and due to mean reversion, as the resilience index is computed from vacancy inflows until mid-May.

Importantly, the change in search direction is not driven by composition changes in the pool of job seekers, as we control for user fixed effects. Appendix Fig. A5 shows the robustness of the results in regressions that do not include user fixed effects.

In a nutshell, job search is not sluggish. The direction of job search seems to react quickly, targeting resilient occupations. However, the observed change in search direction may be driven by the evolution of available vacancies. To account for this composition effect, we analyse how the attention to individual vacancies changes depending on their type.

To do so, we split the sample of vacancies according to their occupations, and we run Regression (2) of the number of clicks per vacancy, in which we include an occupation-group interaction term. We use the following specification: $y_{j d}=\sum_{w} \delta_{w} \mathbf{1}[j \in \mathcal{O}] \times \mathbf{1}[d \in w]+\sum_{w} \beta_{w} \mathbf{1}[d \in w]+\gamma X_{j d}+\varepsilon_{j d}$,

where $y_{j d}$ is the log of the number of clicks on vacancy $j$ during day $d, \mathcal{O}$ is a vacancy subsample of interest, either resilient occupations, or occupations that are more often worked from home. All other notations are previously defined in Section 5.2. Our parameters of interest are the weekly effects $\delta_{w}$. They identify the weekly deviation of the number of clicks on vacancies belonging to subsample 0 compared to clicks on the complement set of vacancies.

Fig. 3 plots the estimated interacted week effects $\delta_{w}$ for the subsample of high home-working occupations in Panel (c), and of resilient occupations in Panel (d). For the year 2020 (plain dots), we find that vacancies in high home-working occupations attract around 5\% more clicks between mid-March and late May than vacancies in low home-working occupations. This contrasts with the periods before the social distancing announcement in 2020, when high home-working occupations do not attract more clicks. Similarly, we find that vacancies in resilient occupations attract around 7\% more clicks in late March and April 2020 than vacancies in non-resilient occupations. We can thus attribute the change in relative attractiveness to the COVID shock. Appendix Fig. A5 shows the robustness of the results in regressions that do not include vacancy occupation and municipality controls.

Heterogeneous effects on clicks per vacancy further confirm that COVID effects on search direction are not only driven by quantitative changes in vacancy composition. If the increase in clicks per user to resilient occupations is only due to the fact that there are more vacancies from resilient occupations available after mid-March 2020, we should not observe any increase in clicks per vacancy from resilient occupations, relative to non-resilient occupations. This section provides evidence that job seekers redirect their search disproportionately to composition changes.

\section{Discussion}

In this section, we discuss what can be learnt from our empirical results in terms of economic shocks and policy effects during the COVID 19 crisis. We first discuss lessons from the decline in job search intensity, then from the short-run increase in labour market tightness, and finally we quantify the implications of increased tightness on expected hires during the COVID-crisis.

Impact on job search intensity We discuss our results within the standard search-and-matching framework à la Pissarides (2000) with endogenous job search effort. Job seekers choose their job search effort $s$ to trade off marginal cost of search and marginal benefit. Formally, this can be written as follows:

$c \prime(s)=\theta m(\theta)\left(V_{e}(w, a)-V_{u}(b, s)\right)$

where $c \prime(s)$ is a marginal search cost function, $\theta m(\theta)$ is the job finding rate per unit of search effort, pinned down by the labour market tightness $\theta$, and $\left(V_{e}(w, a)-V_{u}(b, s)\right)$ is the difference between the value of employment with wage $w$ and non-wage health amenity $a$ and the value of unemployment, which depends on benefits $b$.

During the COVID crisis, higher contamination risk at the workplace or during the commute reduces the health amenity $a$. Job seekers decrease search intensity in response to the corresponding decrease in the net value of employment. This mechanism is consistent with our empirical findings. ${ }^{9}$

In addition, the value of unemployment is likely to increase as the Swedish government increases the unemployment benefits $b$.

\footnotetext{
${ }^{9}$ Note that the health amenity channel is likely to matter less for the effect of the crisis on on-the-job search. Workers searching on-the-job may experience an increase in health risk of the same magnitude in their current job and in their prospective job, so that health risk does not necessarily impact the net value of job switching.
} 
(a) Clicks per user, high vs. low home-working (b) Clicks per user, resilient vs. non-resilient ococcupations

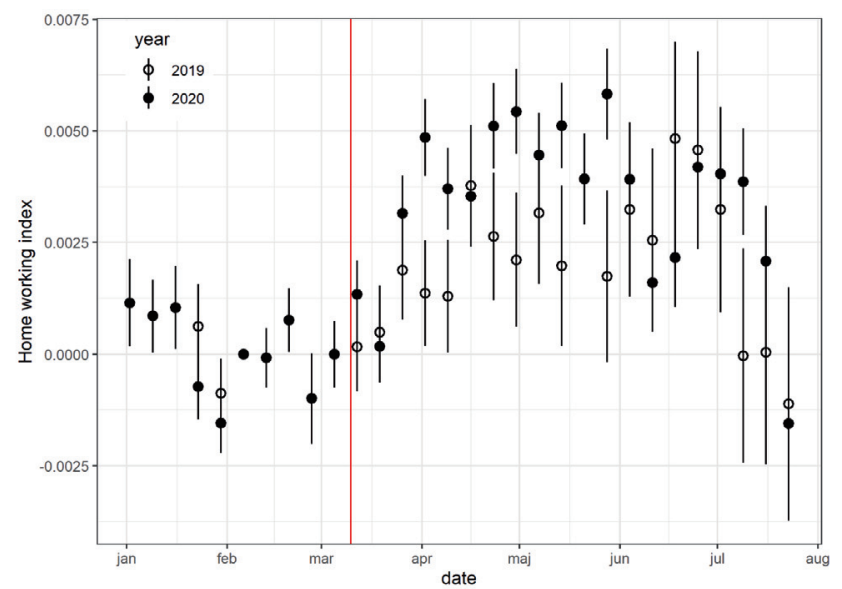
cupations

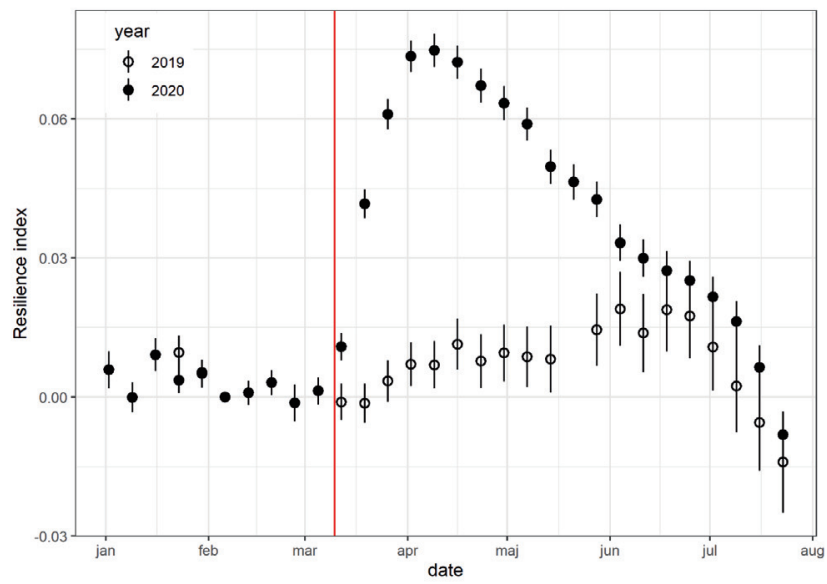

(c) Clicks per vacancy, high vs. low homeworking occupations

(d) Clicks per vacancy, resilient vs. non-resilient occupations
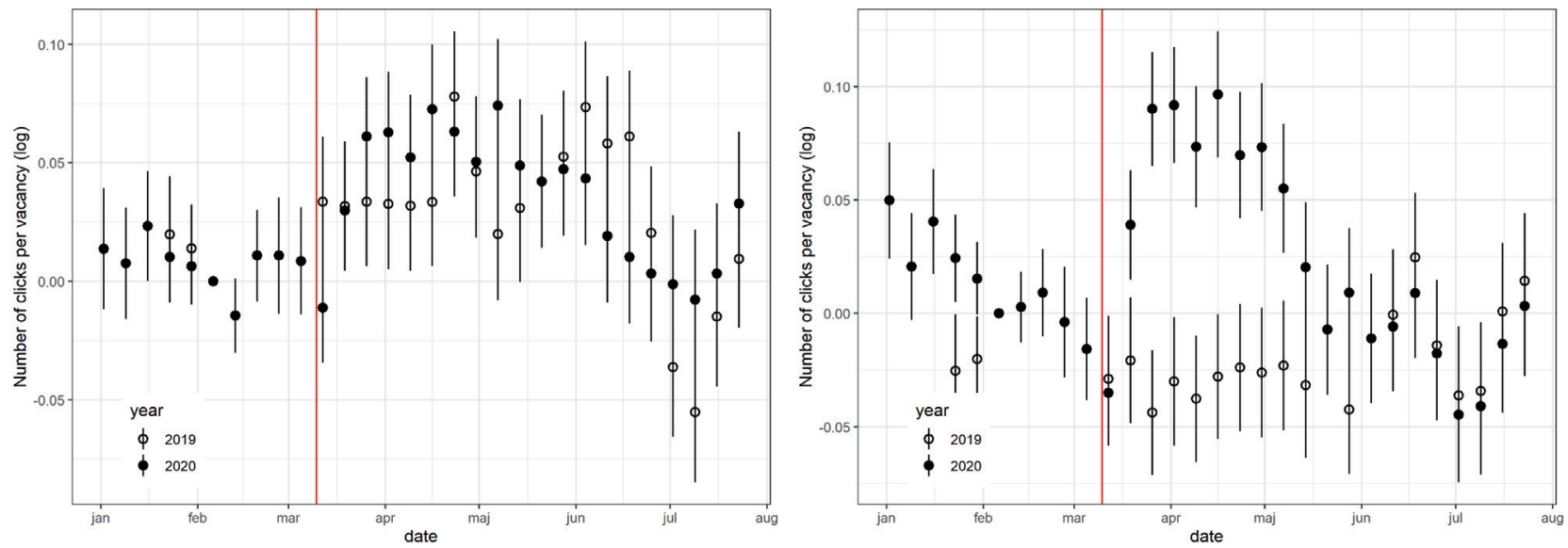

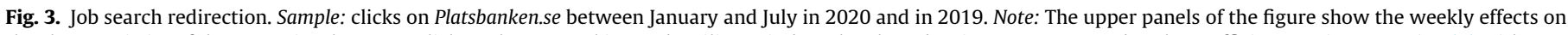

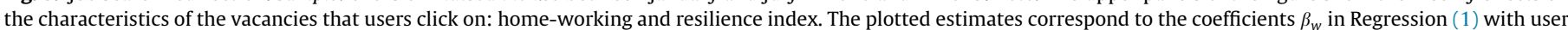

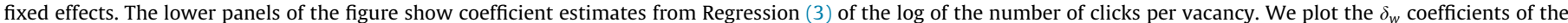

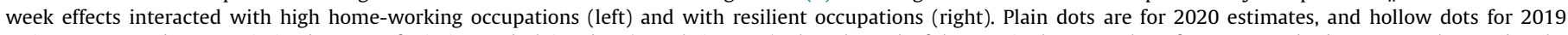

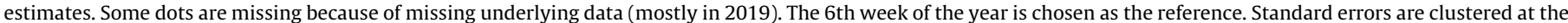

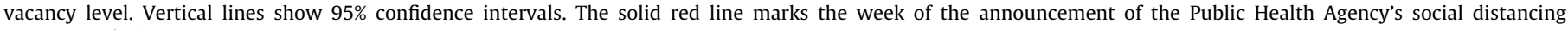
re.commendations.

While there is an extensive literature on the reduction of search effort when unemployment insurance is generous, the Swedish data do not show any break in job search intensity around midApril when the UI reform took place (see e.g. Fig. 2). This is consistent with the evidence recently brought by Marinescu et al. (2020): using the American job board Glassdoor, they find that job search starts to decrease before the CARES Act is implemented.

In the shortrun (mid-March to mid-May), we observe that the effective queue length of workers in front of each job opening is going down. This means that the effective tightness and the job offer arrival rate increase in the wake of the shock, which should increase search effort. According to our framework, job search is the result of the net-value-of-employment channel and the tightness channel. One possible way to rationalise the observed decrease in search intensity is that the former dominates the latter. Another explanation is that job seekers underestimate the shortrun increase in labour market tightness and miss some search opportunities.
Impact on labour market tightness In standard search-andmatching framework, firms are assumed to adjust labour demand by posting vacancies whenever the expected value of a posted vacancy is higher than the cost of posting that vacancy. The freeentry condition leads to the following labour-demand equation:

$\frac{h}{m(\theta)}=\frac{y-w}{r+q}$

where $h$ is the flow cost of having a vacancy open, $m(\theta)$ is the job filling rate, $y$ is the instant productivity of a match, $r$ is the interest rate, and $q$ is the instant probability that the match stops existing. In the short run, when wages $w$ can be assumed exogenous, the labour-demand equation pins down the labour market tightness $\theta$.

The COVID crisis leads to a drop in the match productivity $y$. In the standard model with rational expectations, firms then decrease their vacancy posting to the point that job filling rates increase. This implies that labour market tightness decreases, and this prediction holds even when wages react endogenously, or when the 
productivity shock is temporary. ${ }^{10}$ Our empirical findings show that the effective tightness increases in the wake of the shock. ${ }^{11}$ One possible way to reconcile our simple model with this finding is to consider that the situation from March to May 2020 is off equilibrium, so that the free entry condition does not hold. For example, firms may have not correctly anticipated the sharp decrease in job search and its consequences for job filling rates. While we are not aware of surveys measuring changes in firms expectation about recruitment duration, the increased economic uncertainty reported in Baker et al. (2020) and Altig et al. (2020) is likely to affect firms' ability to correctly predict job-filling rates.

During the COVID crisis, the Swedish government allows firms to use short-time work schemes. The furlough option is not directly modelled in the standard search-and-matching framework. From the employers' perspective, furloughs substitute for new vacancies, driving down tightness. However, the possibility to furlough workers in the future increases the match profitability, increasing tightness. While we have no empirical results to refute the latter upward pressure of furloughs on tightness, we believe that the temporary nature of the furlough scheme makes this intertemporal channel less relevant.

Implications for hires The crisis impact on job search matters as a reduction in job search may amplify the shock on the labour market. To quantify the magnitude of the amplification mechanism, we perform a simple counterfactual analysis. We consider a Cobb-Douglas matching function, which defines the aggregate number of hires as:

$M=m_{0}(s U)^{\eta} V^{1-\eta}$

where the elasticity of matching wrt to effective search unit $(\eta)$ is equal to 0.45 (Petrongolo and Pissarides, 2001; BorowczykMartins et al., 2013; Cahuc et al., 2019). Holding constant aggregate job search intensity $(s U)$, the drop in matches due to the $40 \%$ reduction in new vacancies would be equal to $22 \%$.

Section 5 delivers scale-free estimates of the effective labour market tightness. We thus rewrite the matching function as $M=m_{0} V(\theta)^{-\eta}$ where $\theta=V /(s U)$ is the effective labour market tightness. The differentiation of the matching function then yields:

$d \log M=d \log V-\eta d \log \theta$

In a counterfactual world where search intensity decreases, so that the effective tightness remains to its pre-crisis level, the number of matches drops by $40 \%(=d \log V)$. Reducing further search intensity to the extent that tightness increases by $25 \%$, i.e. the lower estimate in Section 5 , leads to $11 \%$ fewer hires. Thus, the decrease in job search that we observe is a first-order phenomenon for labourmarket outcomes.

\section{Conclusion}

The number of posted vacancies experiences a brutal and persistent decrease since the beginning of the COVID-19 crisis. With a contracting labour demand and an expanding pool of registered unemployed, one could expect, if individual job search behaviors remain at pre-crisis levels, that job-filling rates would increase, initiating a virtuous circle by reducing the cost of hiring for employers.

Job search reacts strongly to the crisis, to the extent that vacancies end up receiving less clicks in the short run. This implies an increase in effective tightness, which is difficult to reconcile with

\footnotetext{
${ }^{10}$ We detail in Appendix C.1 the full equilibrium solutions and comparative statics.

11 The only comparable empirical evidence we are aware of is by Campello et al. (2020) who show using US data from a labour research firm LinkUp that the time to fill vacancies increases, especially for high-skill jobs.
}

a standard equilibrium search-and-matching framework. Our findings, combined with a simple calibrated matching function, suggest that the endogenous response of search intensity may amplify the fall in the number of hirings by at least $11 \%$, on top of the direct effect of labour demand.

We also document that individual vacancies that belong to occupations for which labour demand is more resilient to the crisis, receive more attention than their competitors from other occupations. This last result could be compatible with directed job search models where job seekers strategically revise the value of employment attached to the different occupations as a result of the crisis, especially in relation to their relative health-risk.

The context we study is Sweden, a country with relatively more lenient social distancing recommendations compared with many other EU countries. Consequently, mobility responses and the labour market contraction are slightly less severe during the initial phase of the pandemic which may impact the external validity of our findings. However, as many countries move towards more lenient measures at the onset of the second wave of the pandemic, we believe that our results -pointing to substantial job search responses- should be of high relevance.

Our findings of a large decrease of job search intensity and of a dynamic redirection of job search raise new questions about labour-market policies to be implemented during the COVID-19 crisis. First, policies that bring about strong job search disincentives should be considered cautiously, as they make it more costly for employers to post new vacancies and hire. Second, policy makers may consider wage subsidies to compensate workers for the temporary decrease in the difference between the utility at work and the utility when non-working due to health risk. Third, workers' willingness to search for other jobs than in "normal times" is encouraging as it means that they may respond favourably to policies aiming to bring them closer to the jobs that are available. It also means that sectors and occupations that suffer the most from the crisis are also the most affected by the disaffection of workers, which may increase their hiring costs. From a policy point of view, this might be an additional reason for the government to support the industries that suffer most during the crisis.

\section{Disclosure statement}

Thomas Le Barbanchon declares that he has no relevant or material financial interests that relate to the research described in the paper "Job Search during the COVID crisis."

\section{Declaration of Competing Interest}

The authors declare that they have no known competing financial interests or personal relationships that could have appeared to influence the work reported in this paper.

\section{Appendix A. Supplementary material}

Supplementary data associated with this article can be found, in the online version, at https://doi.org/10.1016/j.jpubeco.2020. 104349.

\section{References}

Adams-Prassl, A., Boneva, T., Golin, M., Rauh, C., 2020. Inequality in the impact of the coronavirus shock: evidence from real time surveys. J. Public Econ. 189, 104245.

Altig, D., Baker, S., Barrero, J.M., Bloom, N., Bunn, P., Chen, S., Davis, S.J., Leather, J., Meyer, B., Mihaylov, E., Mizen, P., Parker, N., Renault, T., Smietanka, P., Thwaites, G., 2020. Economic uncertainty before and during the COVID-19 pandemic. J. Public Econ. 191, 104274. 
Andersen, A.L., T.E. Hansen, N. Johannesen, and A. Sheridan (2020): "Pandemic, Shutdown and Consumer Spending: Lessons from Scandinavian Policy Responses to COVID-19," Working paper arXiv:2005.04630.

Baker, S.R., Bloom, N., Davis, S.J., Terry, S.J. 2020. COVID-Induced Economic Uncertainty, Working Paper 26983, National Bureau of Economic Research.

Banfi, S., Villena-Roldan, B., 2019. Do high-wage jobs attract more applicants? directed search evidence from the online labor market. J. Lab. Econ. 37, 715746.

Barrero, J.M., Bloom, N., Davis, S.J., 2020. COVID-19 Is Also a Reallocation Shock, Working Paper 27137, National Bureau of Economic Research.

Bartik, A.W., Bertrand, M., Cullen, Z., Glaeser, E.L., Luca, M., Stanton, C., 2020. The impact of COVID-19 on small business outcomes and expectations. Proc. Nat. Acad. Sci. 117, 17656-17666.

Belot, M., Kircher, P., Muller, P., 2018. Providing advice to Jobseekers at low cost: an experimental study on online advice. Rev. Econ. Stud. 86, 1411-1447.

Bernstein, S., Townsend, R.R., Xu, T., 2020. Flight to Safety: How Economic Downturns Affect Talent Flows to Startups, Working Paper 27907, National Bureau of Economic Research.

Boeri, T., Caiumi, A., Paccagnella, M., 2020. Mitigating the work-safety trade-off, COVID Econ. - Vetted Real-Time Pap. 2, 60-66.

Born, B., Dietrich, A.M., Mueller, G.J., 2020. Do lockdowns work? A counterfactual for Sweden. COVID Econ. - Vetted Real-Time Pap. 16.

Borowczyk-Martins, D., Jolivet, G., Postel-Vinay, F., 2013. Accounting for endogeneity in matching function estimation. Rev. Econ. Dyn. 16, 440-451.

Brown, J., Matsa, D.A., 2020. Locked in by leverage: job search during the housing crisis. J. Financ. Econ. 136, 623-648.

Brynjolfsson, E., Horton, J.J., Ozimek, A., Rock, D., Sharma, G., Ye, H.Y.T., 2020. COVID-19 and Remote Work: An Early Look at US Data, Working paper.

Cahuc, P., Carcillo, S., Le Barbanchon, T., 2019. The effectiveness of hiring credits. Rev. Econ. Stud. 86, 593-626.

Cajner, T., Crane, L.D., Decker, R.A., Grigsby, J., Hamins-Puertolas, A., Hurst, E., Kurz, C., Yildirmaz, A., 2020. The U.S. Labor Market during the Beginning of the Pandemic Recession, Working Paper 27159, National Bureau of Economic Research.

Campello, M., Kankanhalli, G., Muthukrishnan, P., 2020. Corporate Hiring under COVID-19: Worker Downskilling, Job Flexibility, and Income Inequality, SSRN working paper 3596655.

Coibion, O., Gorodnichenko, Y., Weber, M., 2020. Labor markets during the COVID19 crisis: a preliminary view. COVID Econ. - Real-Time Vetted Pap. 21, 40-58.

Dingel, J.I., Neiman, B., 2020. How many jobs can be done at home?. J. Public Econ. 189, 104235.
Faberman, R.J., Kudlyak, M., 2019. The intensity of job search and search duration. Am. Econ. J.: Macroecon. 11, 327-357.

Forsythe, E., Kahn, L.B., Lange, F., Wiczer, D., 2020. Labor demand in the time of COVID-19: evidence from vacancy postings and UI claims. J. Public Econ. 104238

Google LLC, 2020. Google COVID-19 community mobility reports, https://google.com/covid19/mobility, 2020. Accessed: 20/07/2020.

Hensvik, L., Le Barbanchon, T., Rathelot, R., 2020. Which Jobs are Done from Home? Evidence from the American Time Use Survey, Working Paper DP14611, CEPR.

Hensvik, L. and O. Skans (2020): "COVID-19 Crisis Response Monitoring: Sweden," IZA Country Report.

Johns Hopkins University, 2020. Coronavirus resource center, https://coronavirus. jhu.edu/region/sweden, 2020. Accessed: 24/05/2020.

Juranek, S., Paetzold, J., Winner, H., Zoutman, F., 2020. Labor market effects of COVID-19 in Sweden and its neighbors: Evidence from novel administrative data, NHH Dept. of Business and Management Science Discussion Paper.

Kudlyak, M., Lkhagvasuren, D., Sysuyev, R., 2020. Systematic job search: new evidence from individual job application data. J. Lab. Econ. (June 3, 2013). FRB Richmond Working Paper No. 12-03R, Available at SSRN: https://ssrn.com/ abstract=2191172 or http://dx.doi.org/10.2139/ssrn. 2191172 .

Marinescu, I., 2017. The general equilibrium impacts of unemployment insurance: evidence from a large online job board. J. Public Econ. 150, 14-29.

Marinescu, I., Rathelot, R., 2018. Mismatch unemployment and the geography of job search. Am. Econ. J.: Macroecon. 10, 42-70.

Marinescu, I., Wolthoff, R., 2020. Opening the black box of the matching function: the power of words. J. Lab. Econ. 38, 535-568.

Marinescu, I.E., Skandalis, D., Zhao, D., 2020. Job Search, Job Posting and Unemployment Insurance During the COVID-19 Crisis, Working paper, SSRN.

Mongey, S., Pilossoph, L., Weinberg, A., 2020. Which Workers Bear the Burden of Social Distancing Policies? Working Paper 27085, National Bureau of Economic Research.

Mongey, S., Weinberg, A., 2020. Characteristics of Workers in Low Work-fromHome and High Personal-Proximity Occupations, Becker-Friedman Institute White Paper.

Montenovo, L., Jiang, X., Rojas, F.L., Schmutte, I.M., Simon, K.I., Weinberg, B.A., Wing, C., 2020. Determinants of disparities in Covid-19 job losses, Working Paper 27132, National Bureau of Economic Research.

Petrongolo, B., Pissarides, C.A., 2001. Looking into the black box: a survey of the matching function. J. Econ. Lit. 39, 390-431.

Pissarides, C.A., 2000. Equilibrium Unemployment Theory. second ed., vol. 1 of MIT Press Books, The MIT Press. 